\title{
Defining compulsive exercise in eating disorders: acknowledging the exercise paradox and exercise obsessions
}

\author{
Solfrid Bratland-Sanda ${ }^{1 *}$ (D), Therese Fostervold Mathisen ${ }^{2}$, Jorunn Sundgot-Borgen ${ }^{2}$ and Jan Harald Rosenvinge ${ }^{3}$
}

\begin{abstract}
Recently Dittmer et al. (JED 6:1-9, 2018). suggested a transdiagnostic definition and a clinical assessment for compulsive exercise in adolescents and adults with eating disorders. In this letter to the editor, we extend the transdiagnostic bridge to the DSM-5-criteria for obsessive-compulsive disorders and hence raise the issue of exercise obsession without compulsive exercise actions. We argue that, at least among persons with bulimia nervosa or binge eating disorders, a belief in the need to exercise to control food, weight and shape, does not necessarily imply that the actual exercise behaviour is excessive in nature. In our opinion, the high scores displayed on compulsive exercise screening instruments is therefore an exercise paradox. This paradox may call attention to the fact that because such obsessions can impair quality of life, they need to be addressed in the clinical evaluation and treatment. Therefore, we suggest adding "exercise obsession" as a fourth subtype of compulsive exercise.
\end{abstract}

\section{Proposed definition of compulsive exercise (CE)}

Physical activity, including exercise, as a maintenance factor for eating disorders has been labelled as unhealthy, pathological, destructive, excessive, compulsive, and addictive in nature [1]. Such labels connect to normative conceptions of health, frequency of, and motives for physical exercise. This diversity in conceptions has led to confusion and difficulties in reaching a consensus in the field about the nature of compulsive exercise (CE). Hence, we acknowledge Dittmer et al. [2] who have proposed that $\mathrm{CE}$ may be defined and assessed by two obligatory criteria (A and B), a third optional criterion $(C)$ and three subtypes (levels) of exercise (Dittmer et al. 2018:3).

A. CE defined as 1) excessive that the patient feels driven to perform in response to an obsession or according to rules that must be applied rigidly, and 2) the exercise is aimed at preventing some dreaded consequences or at preventing or reducing distress, often based on distorted beliefs about exercise.

\footnotetext{
* Correspondence: solfrid.bratland-sanda@usn.no

${ }^{1}$ Department of sports, physical education and outdoor sciences, University

of South-Eastern Norway, Campus Bø, Gullbringvegen 36, 3800 Bø in

Telemark, Norway

Full list of author information is available at the end of the article
}

B. The CE is time-consuming (takes more than $1 \mathrm{~h} \mathrm{a}$ day), significantly interferes with the person's daily routine, occupational functioning or social relationship or is continued despite medical injury, illness, or lack of enjoyment.

C. At some point the patient has recognized that the $C E$ is excessive or unreasonable.

D. Subtypes 1) vigorous exercise, 2) marked increase in daily movement, and 3) motor restlessness.

The purpose of such criteria is to identify all aspects of $\mathrm{CE}$, to assist the comparison of research findings across studies, and to make sound clinical evaluation of patients who display CE. However, we are concerned that these proposed criteria may not adequately serve such purposes. We therefore suggest development of the criteria to include the concept of exercise obsession.

\section{The exercise paradox}

The proposed criteria and the subtypes ask for behavioural manifestations, motives to prevent or avoid negative consequences of not exercising, and the personal burdens of CE. Seeking diagnostic parsimony rather than diversity, we argue that the CE-criteria do not appear as a separate or new clinical condition. Rather, they seem

(c) The Author(s). 2019 Open Access This article is distributed under the terms of the Creative Commons Attribution 4.0 International License (http://creativecommons.org/licenses/by/4.0/), which permits unrestricted use, distribution, and reproduction in any medium, provided you give appropriate credit to the original author(s) and the source, provide a link to the Creative Commons license, and indicate if changes were made. The Creative Commons Public Domain Dedication waiver (http://creativecommons.org/publicdomain/zero/1.0/) applies to the data made available in this article, unless otherwise stated. 
to align with, or be close to, the DSM-5 diagnostic criteria for an obsessive-compulsive disorder (OCD) [3]. It may be that an adaptation of the DSM- 5 criteria for OCD is sufficient to identify and manage CE. The alignment with OCD criteria may allow for a further refinement of the understanding and evaluation of $\mathrm{CE}$ due to the distinction between obsessions and compulsions. Thus, development of the proposed criteria [2] should aim to clarify the distinction between obsessions (i.e., rigidly applied rules about a "need" to exercise) and compulsions (i.e., the exercise behaviours). Our concern is that the focus on frequency and motives for exercise (i.e. the excessive part of $\mathrm{CE}$ ) may underestimate the burden from the exercise obsessions, notably among persons with sedentary behaviour. Evidence suggests that the obsessive, but not the excessive, aspect of exercise is related to bulimia nervosa (BN) [4]. Our own research $[5,6]$ supports this as women with $\mathrm{BN}$ or BED may display high scores on CE-instruments despite their objectively assessed low volume of physical activity, which is well below the official recommendations [7]. We have labelled this the "exercise paradox". For instance, obsessive beliefs about the need to exercise may reflect an intention to maintain a self-image as being healthy, to seek the benefits of a socially admired active lifestyle, to counteract the effects of binging, and/or avoid the shame associated with purging. Yet the individual might not be able to translate such intentions into action. Adding defeat in meeting societal expectations of healthy exercise in line with the official physical activity recommendations [7], the exercise paradox can inflict significant psychological burdens. It is our contention that this paradox adds scientific and clinical value to the proposed criteria for CE.

\section{Suggestions for the subtype "exercise obsession"}

Acknowledging the proposed subtypes as well as the exercise paradox, we propose a fourth subtype covering the obsessive aspects, i.e. "excessive obsessions". Prevalence rates of exercise obsessions concurrent with sedentary behaviour in eating disorders lack in the existing literature. In our study [6], 142 women with BN or BED had both valid accelerometer-assessed physical activity and completed the Compulsive Exercise Test (CET). Of these, 20\% with BN and 6\% of BED showed high CET-score (i.e. $\geq 15$ ) yet sedentary behaviour (i.e. $<150$ $\mathrm{min} /$ week with physical activity). In persons without excessive exercise, we are concerned about the risk that the nature and burdens of exercise obsessions may be undetected in clinical evaluation and treatment. We cannot exclude the possibility that such risk may lower the overall treatment outcome for these patients. By contrast, this subtype will enable clinicians to evaluate and approach this paradox in treatment. For persons with this subtype of CE the customary response-prevention approach to OCD may be contraindicative, as we do not want to further reduce the lower level of exercise. Rather, the level should be increased with what is appropriate given the patient's physical and mental health. The volume and type of physical activity should also be synchronized with the progress in reducing the impact of obsessions, and with the overall treatment aim to promote healthy and balanced exercise, and exercise motivated by enjoyment.

\section{Acknowledgements \\ Not applicable. \\ Funding \\ No funding was received for this manuscript. \\ Availability of data and materials \\ Not applicable. \\ Authors' contributions \\ SBS had the initial idea for this manuscript. SBS and JHR wrote the first draft of the manuscript, and all authors have commented and revised the manuscript. All authors have read and approved the final version of the manuscript. \\ Authors' information \\ SBS is an associate professor in physical activity and health and leader of the Eating Disorders, Sports and Exercise Special Interest Group in Nordic Eating Disorders Society. TFM holds a post doc. in exercise science and is a board member of the Norwegian Eating Disorder Society. JSB is a professor in sports medicine, member of the International Olympic Committee Medical and Scientific Expert Group, vice-president of the Nordic Eating Disorder So- ciety, leader of the Norwegian Eating Disorders Society, and Faculty Member of American College of Sports Medicine. JHR is a professor in psychology and former board chairman of the Nordic Eating Disorder Society.}

Ethics approval and consent to participate Not applicable.

Consent for publication

Not applicable.

\section{Competing interests}

The authors declare that they have no competing interests.

\section{Publisher's Note}

Springer Nature remains neutral with regard to jurisdictional claims in published maps and institutional affiliations.

\section{Author details}

${ }^{1}$ Department of sports, physical education and outdoor sciences, University of South-Eastern Norway, Campus Bø, Gullbringvegen 36, 3800 Bø in Telemark, Norway. ${ }^{2}$ Department of sports medicine, Norwegian school of sport sciences, Oslo, Norway. ${ }^{3}$ Department of Psychology, UiT -The Arctic University of Norway, Tromsø, Norway.

Received: 19 December 2018 Accepted: 18 March 2019

Published online: 04 April 2019

\section{References}

1. Cunningham HE, Pearman S 3rd, Brewerton TD. Conceptualizing primary and secondary pathological exercise using available measures of excessive exercise. Int J Eat Disord. 2016;49:778-92.

2. Dittmer $\mathrm{N}$, Jacobi C, Voderholzer U. Compulsive exercise in eating disorders: proposal for a definition and a clinical assessment. J Eat Disord. 2018;6:1-9.

3. APA. Diagnostic and statistical manual of mental disorders (5th ed.) Arlington, VA: American Psychiatric Publishing; 2013. 
4. Adkins EC, Keel PK. Does "excessive" or "compulsive" best describe exercise as a symptom of bulimia nervosa? IntJ EatDisord. 2005;38:24-9.

5. Mathisen TF, Rosenvinge JH, Friborg O, Pettersen G, Stensrud T, Hansen BH, Underhaug KE, Teinung E, Vrabel K, Svendsen M, et al. Body composition and physical fitness in women with bulimia nervosa or binge-eating disorder. Int J Eat Disord. 2018;51:331-42.

6. Mathisen TF, Bratland-Sanda S, Rosenvinge JH, Friborg O, Pettersen G, Vrabel KA, Sundgot-Borgen J. Treatment effects on compulsive exercise and physical activity in eating disorders. J Eat Disord. 2018;6:43.

7. Haskell WL, Lee IM, Pate RR, Powell KE, Blair SN, Franklin BA, Macera CA, Heath GW, Thompson PD, Bauman A. Physical activity and public health: updated recommendation for adults from the American College of Sports Medicine and the American Heart Association. Med SciSports Exerc. 2007;39. 1423-34.

Ready to submit your research? Choose BMC and benefit from:

- fast, convenient online submission

- thorough peer review by experienced researchers in your field

- rapid publication on acceptance

- support for research data, including large and complex data types

- gold Open Access which fosters wider collaboration and increased citations

- maximum visibility for your research: over $100 \mathrm{M}$ website views per year

At $\mathrm{BMC}$, research is always in progress.

Learn more biomedcentral.com/submissions 